\title{
Who Do You Know SDO? Relationships Matter
}

\section{Manisha Mirchandani and Ruth A. Shapiro}

Relationships are two-way streets, connections between people, and donors know it - especially in Asia. As discussed in the chapter on philanthropists, donors use their relationships to engender trust and to guide decisions about funding. It's no surprise that our studies show successful social delivery organizations (SDOs) in Asia are adept at cultivating their own sets of relationships. Here we detail their strategies of employing relationships to get things done.

The most straightforward way to engage a helpful network is to have one in place from the start. Many successful SDOs begin with a founder or board member already established as a leader. Our board members are excellent examples. Ronnie Chan has been involved with numerous nonprofit organizations for years, has led the Asia Society, and helped me to create first the Asia Business Council and now the Centre for Asian Philanthropy and Society. Lizzie Zobel is the co-founder of Sa Aklat Sisikat Foundation, a philanthropy devoted to increasing literacy, is the chairwoman of Teach for the Philippines, and sits on the board of the Population Council. Daniel Tsai sits on the board of his alma mater, the University of Southern California, and oversees four charitable foundations in Taiwan.

M. Mirchandani

CAPS, Hong Kong SAR, China

R.A. Shapiro

CAPS, Hong Kong SAR, China

(C) The Author(s) 2018

R.A. Shapiro et al., Pragmatic Philanthropy, https://doi.org/10.1007/978-981-10-7119-5_5 
Jamshyd Godrej has been on the boards of the World Resources Institute, the World Wildlife Fund of India, Shakti Sustainable Energy Foundation, the Council on Energy, Environment and Water, and the National Center for Performing Arts. This group of leaders has made exceptional contributions to the charitable sector. Clearly when a person like Lizzie Zobel creates a new nonprofit organization, she not only legitimizes the effort but offers to it potential resources in ways that those without her network cannot.

In Asia, the involvement of the elite directly starting, running, and governing social delivery organizations is increasing with the rise in wealth. This "do it yourself" mentality-a spirit of philanthropic entrepreneurialism-is evident in many thriving SDOs. Elites have stepped in where government or existing social institutions have left a social need unfilled. One example is Nellie Fong, a legislator and chartered accountant, who caught the attention of Chinese authorities with her expertise on international tax law in the 1990s. She joined the transition team for the handover of Hong Kong from British to Chinese sovereignty and became aware of plans by China's provinces to send symbolic gifts for the occasion. Seeing an opportunity to respond in kind, she suggested a gift from the people of Hong Kong: a train that which could criss-cross mainland China, offering mobile health care to those who needed it. This idea was rooted in the very concept of guanxi, as a way for the people of Hong Kong to reciprocate the gifts received from the Mainland, and as a way of fostering goodwill.

With blessings from Hong Kong and Mainland officials, the Lifeline Express departed from Hong Kong on July 1, 1997, carrying eye doctors and equipment to perform cataract surgery in rural areas of China. Serving 130,000 beneficiaries and reaching 27 provinces and 120 cities since then, Lifeline Express was made possible through the tenacity of an insider like Fong. Her clout on both sides of the border helped her to garner support for the Eye Train concept, earning approval from two state-level ministries alongside multiple provincial and local officials in China- a prerequisite for nonprofits to operate openly and effectively in the country. Fong recognized her unique role as a convener to the extent that she personally drew up banquet seating arrangements when she brought people together in support of the cause. She used her personal guanxi to get the Eye Trains up-and-running and offered Lifeline Express as an opportunity for people to accrue it themselves: a seat on the board of the Lifeline Foundation would become an attractive platform for China's most influential current and former officials.

In Singapore, the Lien Foundation began with another well-established leader. Banker and entrepreneur Lien Ying Chow started the foundation in 1980 as a means of giving back to society. When it added professional 
staff in 2005-2006, its first hire was a former official and businessman, Lee Poh Wah. Brought on to lead Lien AID, an organization made "to champion the foundation's interests in water and sanitation," Lee encouraged its growth at a time when there was a paucity of SDOs focused on waterspecific interventions.

Lien AID's substantial support from the Lien Foundation (about US\$12 million by 2014,80 percent of its operating income) enabled it to experiment with new solutions for improving the quality and availability of drinking water in the nearby countries of China, Vietnam, and Cambodia. With its financial security, Lien AID could experiment until discovering solutions that flourished in the local context. The organization's first project in Cambodia, in 2007, was as Lee put it, "our most spectacular failure." The hygiene complex constructed in an urban slum in the capital city of Phnom Penh became a target for resentment in the community and was eventually dismantled in 2012 to make way for property development in the fast-growing city. But Lien AID persisted in Cambodia with various water-related interventions, launching 43 successful community-based water social enterprises by May 2015. Today, Lee Poh Wah heads up the Lien Foundation as chief executive officer while Laurence Lien, grandson of Dr. Lien, serves as chairman of the board. Water and sanitation remains among its three areas of focus, and the foundation continues to be Lien AID's most generous benefactor, providing 91 percent of its income in 2013-2014. Responding to a gap in the social delivery sector, Lien AID was established as a "start-up," to bring about fresh ideas and to challenge existing norms. This was possible only with patient capital from its parent foundation, itself started by a leader in the community who could afford the risks associated with innovation.

Many donors move one step away from creating organizations themselves, looking to those who are already trusted members of their network. When Wash SyCip, Filipino business tycoon and founder of the Asian Institute of Management, got behind a project, there was one critical factor that drove his decision to do so: "I only fund organizations where I know and trust the leader," he said. He is not alone. Asian business has traditionally been conducted on the basis of good relations, as exemplified by the concept of guanxi in China. Translating roughly into English as "relationships," the phenomenon of Chinese business underpinned by personalized networks of influence has been closely studied in modern management literature. In the Oxford Handbook of Asian Business Systems, INSEAD Professor Michael Witt argues that business groups based on relationships exist due to the lack of rule of law and its formalized enforcement mechanisms. ${ }^{1}$ There is great mistrust, which propels business people to stick with those they know. 
Founders thus often establish a board of trustees where the relationships among them help move the organization forward. Of course, this is also true in successful organizations around the world, but given the cultural traditions and historical context of the region, it is particularly important in Asia. Bainian Vocational School (BNVS), for instance, chooses its board of trustees strategically to meet its mission in job placement. BNVS board members are well positioned both to help financially and to provide access to future company employers.

The China Medical Foundation (CMF) takes an additional step in targeting successful business leaders for its board. Unlike many other organizations, it requires a financial commitment of at least US\$10,000 per annum from each board member. Many nonprofit organizations encourage board giving, but CMF's requirement is made explicit for every incoming board member. In addition to financial support, CMF's board members are often in positions to help reach out to potential donors and government partners in China. With "skin in the game" through their financial investment, CMF's board is highly committed and involved with its success in China.

Given the importance of relationships in Asia, it is natural for boards of trustees to further organizations' causes. We also found that for those organizations that begin within the elite, the board offers productive social empowerment. Outside such circles, boards tend to have less reach, and are often comprised of friends and family, when such a board exists at all. Closing this gap of experience can help many SDOs in Asia, as they increase the capacity of their boards to help achieve their missions.

\section{Well-connected: Pre-existing Relationships}

Of the 30 Asian SDOs studied, there remain several started by practitioners from outside of business and political circles. Dedicated and resourceful founders have established some of Asia's most prolific nonprofits; but no such success is a solitary affair, as our studies show. Organizations begun by outsiders often receive the help of benefactors encountered on the way to development. Insiders in their respective fields have provided support ranging from financial, or in-kind, to something more akin to guanxi, as founders tap into the resources and trust of well-connected friends to bring their ideas to fruition.

Jaime Aristotle Alip did just this in the Philippines, after he founded CARD Mutually Reinforcing Institutions (MRI), a microfinance network, 
in 1986. Alip was not a member of the elite himself-CARD was famously established with a 20-peso (US\$1) bill and a mechanical typewriter for tapping out proposals - but his pre-existing relationships were critical in getting the idea off the ground in the first place. As Alip described it; "Perhaps because of pity, my friend's company accepted my proposal and provided US\$10,000." CARD's first donors were acquired through contacts Alip had acquired from his time at the Philippine Business for Social Progress (PBSP), a social development foundation established by a Philippine business consortium. With a little help from his friend - the Japanese foundation Asian Community Trust is a long-time international funder of the PBSPAlip was able to take the first steps towards fulfilling his vision for a bank owned and managed by landless poor women. Today it has 1 million loans on its ledger and protects 8 million people under its insurance schemes.

Alip didn't stop there, nor did the productive use of his relationships. CARD became a trusted and respected organization, and Alip had become acquainted with Wash SyCip, a successful business leader who provided most of his philanthropy to improve the life chances of poor rural children. Although CARD was a microfinance organization without experience in the education sector, SyCip provided P20 million (US\$430,000) for a pilot CARD MRI educational loan program tested in two rural provinces. It succeeded, and the program expanded nationwide. SyCip himself put in US\$ 1 million and through his own network convinced several New York financiers to also offer substantial funding for the further development of the program.

Support from India's business and political elite was also a major driver behind the Council of Environment, Energy and Water (CEEW), an Indian policy think tank. Leaving an illustrious career in international development, Arunabha Ghosh ghostwrote a proposal for a world-class environmental think tank. He shared it with former minister Suresh Prabhu and business leader Jamshyd Godrej, chairman of Godrej \& Boyce Manufacturing Company. They not only shared his vision but had been advocating for the establishment of such a research organization for some time. "I was assured that the individuals who would become our board members were seeing the gaps that were resonating with me," said Ghosh. "If they were not there, I wouldn't necessarily have come back to India and started something."

CEEW began operations in August 2010 in a sparsely furnished room in Gurgaon, operating with two staff members and a donation from Godrej of INR 5000 (around US\$100 at the time). It is now internationally recognized as one of India's best think tanks and serves as an example of guanxi coming full circle, with a multiplying effect. CEEW 
added to its board of prominent trustees, which now includes business leaders S. Ramadorai, Deepak S. Parekh, and Anil Kakodkar, former chairman of the Atomic Energy Commission. All are active in promoting the organization's research and agenda for an evidence-based approach to sustainable development. In 2015, Prabhu, now minister for railways, released a CEEW policy briefing on the solar potential of Indian railways.

\section{Bypassing the Trust Deficit}

Like Wash SyCip, supporters of these SDOs put their faith in personal affiliations they perceived to be trustworthy, transparent and accountable. Such relationships provide a starting point for charity that differs from many places in the West, where donors may seek a particular organization more than a known individual. Relationships matter elsewhere, too, and a well-placed champion is an asset anywhere in the world, but in Asia, a personal connection becomes especially valuable in the absence of due diligence mechanisms.

A trusted domestic broker has the capacity to boost an SDO's credibility. In Thailand, with its complex interaction between business, the military, and the state, the royal family brings unique credibility to public ventures. Revered by the Thai people, the royal family generally stays above the fray of political strife, and are perceived as trustworthy actors in public life. Organizations who receive the royal seal of approval, such as the Foundation for Slum Child Care (FSCC) are accredited with a level of confidence that is beyond reproach in the Thai context. Although the FSCC had already enjoyed an affiliation with the elite and international accolades, royal patronage changed the game for its co-founders, Nongyao Narumitrekakarn and Prateep Ungsontham. Narumitrekakarn, a respected socialite, became aware of the squalid conditions in Klongtoey Slum when her brother worked as an architect on a public project there. While visiting, she met activist Ungsontham who was raised in the slum and had established a "one-baht-a-day" school at her home for the many neighborhood children who did not have access to education. Ungsontham had already had local success. In 1972, she was photographed standing in front of a tractor that had been sent by the Bangkok Metropolitan Authority to demolish the school and reclaim the land. For her efforts to save the school, she was awarded the Ramon Magsaysay Award for Public Service in 1978 and the John D. Rockefeller Youth Award for her "outstanding contribution to mankind" in 1981. 
That same year, the two women established FSCC to provide day care for slum children who were left to fend for themselves while their parents worked. Together, the duo caught the eye of HRH Princess Galyani Vadhana Krom Luang Naradhiwas Rajanagarindra, a prolific philanthropist, who was intrigued by a profile in an English-language newspaper, Bangkok Post, on a "nursery for the poor." Princess Galyani's patronage of the FSCC was a turning point for the organization, bringing recognition and confidence along with the royal seal of approval. They went on to raise the funds needed to expand operations to other slum districts within Bangkok, and eventually establish a nationwide training network to offer official certification for child care providers.

When SDOs lack direct access to the elite, intermediaries play an important role in connecting deserving organizations with potential benefactors and supporters. In India, where a 2013 Companies Act mandates that 2 percent of after-tax income be directed to corporate social responsibility activities, a number of intermediary organizations have emerged to help businesses and individuals make sense of their giving. Among these are GiveIndia and Guidestar India, online portals that connects donors with screened nonprofits, and Dasra, providing bespoke research and management services to donors while working to build the capacity of recipient organizations. More informal groups in India also act as trusted brokers, such as Caring Friends India, which businessman Ramesh Kacholia founded to "act as a bridge between outstanding NGOs and donors." Over the years, it has identified 30 such NGOs across 10 states in India, one of which is Dilasa Sanstha, a grassroots organization aiming to alleviate the suffering of farmers in drought-prone areas, by providing microcredit and the adaptation of indigenous irrigation systems.

Babu C. Joseph, former chief executive officer of the Axis Bank Foundation, heard of Dilasa Sanstha through Caring Friends. He eventually supported it with a grant of around US\$1.8 million, helping more than 8000 farmers and extending credit to 43,000 beneficiaries. Caring Friends is not a registered NGO and has no bank account, ${ }^{3}$ but it has built an informal network of Kacholia's friends and supporters who are bound together by a wish to do well. "The common cord that binds them is a genuine desire to reach out to those who need our care," writes Joseph. "The beauty of the association is its simplicity and informality and this friendship has resulted in providing support to several organizations." 4 In this sense, intermediaries such as Caring Friends have successfully leveraged their own guanxi to help worthy organizations in India that are deficient in it. 
Organizations can also develop helpful relationships by first attracting international recognition. When Dutchman Willie Smits stumbled across Suara Alam, it was an Indonesian grassroots radio station with a mission to highlight local environmental injustices. Smits, an experienced philanthropist, provided it with funds to set up a TV station and get on the radar of international organizations. The group rebranded as Telapak and went on to work directly with local communities to establish sustainable logging cooperatives, creating livelihood options for farmers as opposed to illegal poaching. For this work, it received awards in social entrepreneurship from the Schwab and Skoll foundations, and Telapak president Ambrosius Ruwindrijarto won the prestigious Ramon Magsaysay Award for Emergent Leadership in 2012.

Such accolades have a multiplying effect, attracting donor funding from foreign governments and foundations seeking to get behind a tested organization that meets their strategic objectives in Indonesia. Many of these organizations lacked visibility in Indonesia's nonprofit sector, and Telapak became one of the few trusted names for many international funders in a notoriously opaque sector. This confidence eventually transferred to multinational companies, who turned to Telapak for advice. It now provides advisory services to large corporations operating in the country on how to work with communities in a sustainable way, and in 2014 this income comprised 25 percent of its total revenues. In a country such as Indonesia, which has historically been beset by corruption, international accolades such as those showered on Telapak amount to a form of due diligence where credible actors in the nonprofit sector are otherwise difficult to locate and verify.

Yang Lihe provides another example of how a founder's long-time international connectivity can prove critical to the success of an SDO. Yang, a former village doctor, became a leading researcher on leprosy, working for the Chinese government's main research center and as an advocate for patient rights. He also founded HANDA in 1996, a GONGO (government-operated NGO) providing services treating leprosy in 12 of China's 23 provinces. To support its mission, Yang leveraged the connections of his long career in public health, as a university researcher, and as a government official. While government support made the creation of HANDA possible, it is these additional relationships that have enabled its growth. HANDA's first major donor was the corporate foundation of Novartis, the Swiss pharmaceutical company, and international sponsors remain its lifeblood today, providing 73 percent of HANDA's income in 2014.

In a broad sense, relationships offer Asians a way around lack of trust in the system. In nations where regulators do not require transparency or accountability, donors need other sorts of reassurance that their money will 
be well spent. Traditionally, personal networks have filled that gap. Today, new means to conduct due diligence have entered the marketplace through the use of technology, and such technology is helping organizations take on roles of trusted advisors, allowing people to sustain communities where none had existed before.

Indonesia offers a prime example of technology empowering new relationships. They have been crucial to the success of the Academy of Sharing, Akademi Berbagi in the Bahasa, a national social movement for skill training with media personalities and business leaders offering free face-to-face classes for young people. It began with a tweet: when founder and PR consultant Ainun Chomsun went online in search of career information, she sent a public message over Twitter to Subiakto Priosoedarsono, founder of one of Indonesia's top advertising firms, soliciting his advice.

"I want to learn to be a copywriter, Mr. Bi, tell me how?" she tweeted.

"I teach, you interested?" Subiakto tweeted back a few minutes later.

The exchange cumulated in him offering to teach a free class at his office to a small group, for which word spread quickly over social media. Dozens of aspiring copywriters attended. The movement for free-of-charge skills training grew, with teachers drawn from Indonesian business and media. Through social media, Akademi Berbagi had blossomed into a national public platform open to all for learning and sharing with experts, with classes coordinated online and conducted offline. Since that first copywriting class in 2010,30,000 students have attended some 1000 classes, which were led by 200 teachers assisted by an equal number of volunteers. Twitter provided an open platform for the genesis of Akademi Berbagi, requiring the organization to be an open, transparent operation. Its success offers a new way for SDOs to think about how to leverage the public forum provided by social media to build trust in lieu of pre-existing guanxi.

Throughout Asia, there are more and more initiatives applying technology to enhance transparency and gain trust. In Hong Kong, WiseGiving is an online platform allowing potential donors to look under the hood of Hong Kong-based SDOs to see how each organization spends the funds it raises. In Singapore, the National Philanthropy and Volunteer Center is a government-backed agency aiming to improve efficacy and transparency of SDOs while aiding philanthropists to make informed decisions. They too have constructed an online platform to facilitate this process. 
Throughout Asia, the rise of social media has also empowered and enabled the citizen watchdog movement, curtailing those trying to exploit the system or engage in fraud. While these efforts are still in their early days, the trajectory of the trend is clear. Citizens are creating alternative mechanisms to fund and oversee social development initiatives with and without the inclusion of the traditional elite.

\section{Conclusions: Strategies for GUANXI In the Social Delivery Sector}

Guanxi persists as a currency of trust in the social delivery sector, rooted in the context of community and family in Asia and bolstered by weak regulatory environments and a resulting dearth of trust. New organizations face barriers to financing and support, given wariness on the part of philanthropists and donors toward homegrown institutions. "Donations can be made only when these fundamentals [infrastructure, legal system and human resources] are all in place," said Chinese philanthropist and founder of Alibaba, Jack Ma. "That's why I think giving donations to charities is more difficult than earning money," he said. ${ }^{5}$

In this context, founders from or close to the elite of society have been best positioned to achieve success across the 30 SDOs studied. Fong of Lifeline Express and Lien of Lien AID were able to leverage their considerable personal resources to move their own projects ahead. Meanwhile, Alip of CARD MRI and Ghosh of CEEW benefited from their insider status acquired from years of building relationships and providing advice as national experts in their respective fields. On the surface, these observations would be disheartening for less well-connected, aspiring SDO founders with bright ideas. But SDOs within the study have deployed various other tactics to garner credibility and gain access to funding and resources.

Other methods of maximizing relationships include:

Seek alternative accreditation: Soliciting international recognition gave Telapak credibility to attract funding and raise its profile, especially among international funding agencies looking to expand their activities in Indonesia. Co-founder Ungsontham's international profile as a slum activist similarly drew attention from international donors to FSCC, but it was royal patronage that ensured its domestic longevity. Getting on the radar of international organizations, including those highlighting 
the work of high-performing SDOs, can serve as a fillip to future prospects. But whether this strategy is viable for an SDO depends highly on their aspirations and the local context.

Cultivate relationships with intermediary organizations: In India, where nonprofits have to register under the Foreign Contribution Regulation Act to receive funds from overseas, aspiring to recognition among international supporters might not be a viable strategy. In such cases, intermediary organizations can connect donors and nonprofits, and there are many in India as a result of the regulatory environment. Organizations such as Dasra, Guidestar India and GiveIndia offer a clearinghouse function by vetting charities and helping them develop positive relationships with engaged donors.

Many such intermediaries actively help SDOs build confidence among donors by developing their internal skills in management, financials, and operations. They also have created optional accreditation systems to help SDOs improve their appeal to donors. The China Social Entrepreneur Foundation (You Change) is currently rolling out a system assessing social entrepreneurs by a number of metrics to become certified by You Change. WiseGiving and NVPC have already established platforms to aid worthy organizations.

Focus online: The case of Akademi Berbagi is an unusual one: few organizations were born on the basis of a tweet. However, it does illustrate the extent to which the operating environment has changed for SDOs, offering new ways in which they can take advantage of changing dynamics. SDOs can directly engage with debate and even shape the discussion of philanthropy through social media, using its platforms to build up credibility with the public. Already, organizations such as Give India are following in the footsteps of Guidestar in the United States and Europe, using an open-source database for organizational data, allowing donors to make their own assessments. Information availability and data is much patchier in Asia, with its inconsistent reporting requirements and varying attitudes toward transparency, but if the case of Akademi Berbagi is anything to go by, those organizations able to harness the Internet improve their chances of thriving.

These strategies, alone or in combination, can help an SDO work around a shortfall of guanxi, a lack of access to elite resources and support. Leveraging relationships in some manner will be crucial for a new organization, as it has been for each of the SDOs studied across Asia. For many of them, pre-existing relationships played a critical role, either through founders who were well placed to draw upon trusted relationships with 
members of the elite or by those founded by a member of the elite themselves, investing their own resources and relationships to the benefit of the SDO. Others found their way to productive relationships through outside accolades or assistance, or through social media.

In none of those cases do relationships provide all that organizations need. They must still work at building transparency, accountability, and impact measurement, especially in Asia, where the trust deficit remains as a legacy of an unclear regulatory environment. Registration and reporting requirements vary, but in many places, these appear to be insufficient to gain the trust of donors and supporters without the credibility brought by guanxi.

\section{Notes}

1. Witt, Michael A. and Gordon Redding. The Oxford Handbook of Asian Business Systems. Oxford University Press, Oxford, UK, 2015.

2. "CARD MRI, An Example of Microfinance Success." Asian Institute of Finance, Manila, Philippines, 2013.

3. Dutta, Anirudha. "The Power of One." Forbes India Blog, July 2, 2013. http://www.forbesindia.com/blog/beyond-the-numbers/corporateindia-and-csr/. Accessed June 21, 2016.

4. Caring Friends: Helping Good NGOs Perform Better, Mumbai, India. https://sites.google.com/a/caringfriends.in/caring-friends/testimonials. Accessed June 21, 2016.

5. http://www.scmp.com/news/china/money-wealth/article/1858697/ its-harder-donate-money-chinese-charities-earn-it-says. Accessed September $16,2015$.

Open Access This chapter is licensed under the terms of the Creative Commons Attribution 4.0 International License (http://creativecommons.org/licenses/ by $/ 4.0 /$ ), which permits use, sharing, adaptation, distribution, and reproduction in any medium or format, as long as you give appropriate credit to the original author(s) and the source, provide a link to the Creative Commons license and indicate if changes were made.

The images or other third party material in this chapter are included in the chapter's Creative Commons license, unless indicated otherwise in a credit line to the material. If material is not included in the chapter's Creative Commons license and your intended use is not permitted by statutory regulation or exceeds the permitted use, you will need to obtain permission directly from the copyright holder.

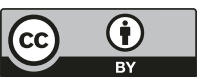

